Case Report

\title{
Active Learning Augmented Reality for STEAM Education-A Case Study
}

\author{
Joanna Jesionkowska ${ }^{1, *(\mathbb{D})}$, Fridolin Wild $1,2, * \mathbb{C}$ and Yann Deval ${ }^{3, *}$ \\ 1 Performance Augmentation Lab, Oxford Brookes University, Headington Rd, Headington, \\ Oxford OX3 0BP, UK \\ 2 Institute of Educational Technology, The Open University, Walton Hall, Milton Keynes MK7 6AA, UK \\ 3 Independent researcher, Centre de la Marionnette de la Fédération Wallonie-Bruxelles, ATLAS, \\ Rue Saint Martin, 47-7500 Tournai, Belgium \\ * Correspondence: joanna.jesionkowska@brookes.ac.uk (J.J.); f.wild@open.ac.uk (F.W.); \\ yann.deval@gmail.com (Y.D.)
}

Received: 10 April 2020; Accepted: 28 July 2020; Published: 4 August 2020

check for updates

\begin{abstract}
Immersive technologies are rapidly transforming the field of education. Amongst them, Augmented Reality (AR) has shown promise as a resource, particularly for education in Science, Technology, Engineering, Arts, and Mathematics (STEAM). There are, however, few teachers deploying this new medium in the classroom directly, and, consequently, only a few, elect students benefit from the AR-enriched offers. Curricula are already overloaded, and schools generally lack developmental resources, thus leaving no room for experimentation. This situation is further aggravated by the too few educational applications available with sufficient learning content. In this article, we investigate the method of Active Learning for the teaching of STEAM subjects, using a format where students are tasked with building an AR application as part of their learning. We evaluate the applicability of the Active Learning for STEAM subjects with a qualitative, case study approach, applying the workshop format as an extracurricular activity in our work with students from a range of secondary schools in Oxford. We discuss how the format works, so it can be embedded into regular curricula, not just as an extracurricular activity, also providing an overview on the involved teaching units and rationale. All teams in our preview audience of the case study succeeded in building working applications, several of impressive complexity. Students found that the lessons were enjoyable and AR technology can enhance their learning experience. The Active Learning method served as a catalyst for students' skills development, with the case study providing evidence of learning to code, working with a physics simulation engine, ray-tracing, and geometry, learning how to manage teams and interact with other students/instructors, and engineering a working prototype of a game. We consequentially argue that combining the STEM subjects and the arts, using the proposed Active Learning format, is able to provide a more holistic and engaging education.
\end{abstract}

Keywords: augmented reality; education; STEM; STEAM; active learning

\section{Introduction}

STEAM skills (Science, Technology, Engineering, Arts, and Mathematics) are becoming more important than ever as society is entering the Fourth Industrial Revolution (Industry 4.0)—technological, economic and societal change characterized by the fusion of the digital, biological, and physical worlds, as well as the growing utilization of new technologies. STEAM skills are the key to the advancement of the future world and are likely to be the foundation of some of the highest growth businesses [1,2]. These skills are important for a range of industries from manufacturing to the arts [3]. The supply of candidates in engineering (and more broadly, STEAM) occupations is not keeping pace with 
demand. Many companies are struggling to upgrade the skills of their employees in cost- and time-efficient ways, losing ground to their competition [4]. Many societies are experiencing a STEAM skills crisis [5]. There are many reasons: poor perceptions and lack of interest in engineering and science jobs, low attainment and progression in science, technology, engineering and mathematics subjects at school, further and higher education, and young people making career choices outside of engineering occupations [6]. Young people are increasingly disengaged from STEM, which manifests itself in reducing enrolments in courses in those STEM subjects, which will be critical to the future economic growth [7].

The last review of the national curriculum in the UK was done in 2012. The current curriculum is very broad, with a large amount of material and a fixed number of hours for delivery [8]. As a result, critics claim that students have only a surface level of understanding in many areas [7]. We believe that the pedagogical solution to this challenge can be found in switching from lecture-based frontal teaching to an active learning approach that facilitates deeper understanding of theory and principles. Such practical, hands-on, project-based learning allows students to formulate, challenge, realize, and validate ideas in a more holistic manner, while - through the collaboratively achieved learning outcomes-rewarding their efforts with tangible results.

In this study, we investigate using Augmented Reality (AR) to engage students to learn STEAM subjects, enabling them to develop their own AR applications. We elaborate, trial, and evaluate a workshop template, the Active Learning AR format, for its ability to contribute to closing the STEAM skills gap.

\subsection{Understanding of STEAM (And How Do We Use It)}

There has been an historic tendency in the education system to require students to choose between The Arts and The Sciences. Those focusing on science subjects are often deprived of developing their artistic skills, while those selecting arts may not be given the chance to enhance their technical skills [9]. Such a framework is creating artificial disciplinary boundaries, limiting students' knowledge and skills development only in one direction. Famous historical figures seem to highlight the importance of holistic education, such as Leonardo Da Vinci, who was simultaneously a painter, mathematician, and scientist, seamlessly integrating arts and science. Traditional STEM education focused on developing mainly technical competence. Innovative problem-solving, however, requires the introduction of creative thinking, a holistic approach that integrates an artistic component with technical skills [10]. Adding an 'A' to the 'STEM' acronym makes 'STEAM', a hot mix that integrates the arts directly into the curriculum and instruction of areas of science, technology, engineering, and mathematics. Such strategy brings out the synergy between art and engineering and helps educating the "whole child" [11]. Instead of separation of concerns, it establishes grounds for cross-disciplinary innovation.

In this article, we describe how Augmented Reality technology can be used in a novel workshop format to develop a range of skills, both equally technical and artistic (see Section 2).

\subsection{Past Research on Augmented Reality in Education}

AR has developed rapidly and it is about to become a mainstream technology. AR is a technology that enables the interaction between the real world and virtual objects. AR has a unique quality to provide a direct link between the physical reality and the virtual information about that reality [12]. It provides a real-time direct or indirect view of a physical world that is enhanced by adding virtual information to it [13], overlaying virtual information onto it. The AR technology progress has been seen not only in the R\&D laboratories, but also in industry and by general consumers in society. There are also many examples of using AR technology in educational settings, e.g., in Higher Education or workplace training $[14,15]$. AR, however, is still a novelty to most, and its use in the classroom is therefore typically rather limited.

Research has shown, however, that the use of AR in education can transform the school environment to a more technology-friendly one, with the potential to embed simulations into the real world that 
otherwise are inaccessible (like a simulated Mars experience), expensive (simulating a DNA sequencer), or dangerous (like simulating surgery). AR can provide deeper learning opportunities by offering a unique mix of both real and virtual environments [16]. Akçayır and Akçayır [17] list several values of AR in learner outcomes, pedagogical contribution and interaction. AR can enable students to have different and effective learning experiences [18], helping learners to develop skills and knowledge that can be learned in other technology-enhanced learning environments, but in a more effective way [19]. AR supplies authenticity to content and interaction, which, in turn, leads to better learning performance and encourages motivation to learn [20]. AR enables physical and cognitive immersion with the learning material, and thus allows for collaborative and interactive work on complex and abstract concepts [16], making learning easier by concretizing these abstract concepts. AR has been shown to attract student attention, increase content understanding and long-term memory retention, increase student motivation, improve collaboration [21], and generate a positive attitude [22]. Integrating AR into class activities has been shown to increase student learning achievement, contribute to students' long-term retention of the concepts, and helps students to understand and analyze the problem scenarios in more depth [23]. Chiu et al. [24] show that the use of AR can increase the level of participation, understanding, and learning, three key elements of all educational systems' targets. Nevertheless, many teachers are untrained to use AR. Besides, there is an ongoing critical shortage of specialist teachers.

Research shows clearly that, when integrated well, AR has the potential to support classes with stunningly engaging holographic content, rendering lesson contents more apprehendable, while providing an unprecedented sense of immediacy. Lessons where AR is used are more fun and enjoyable. This technology has a potential to increase student participation in class and promote their positive attitudes towards STEAM subjects.

There is, however, still too little research on how to introduce AR in schools, leaving teachers ill-equipped and discouraged to utilize AR in the classroom. Teachers require more support with didactic knowledge in order to benefit from AR.

\subsection{Challenges in Relation to the Use of AR in STEAM Education}

Lectures and laboratories are still the most commonly used approach in STEAM subjects. Generally, active methods, like project- and inquiry-based learning, which are student-centric practices, still often fall short in the harsh reality of the education system [25]. There are many systemic barriers that can prevent teachers from deploying such innovative methods: a rigid curriculum scope and sequence, regimented benchmark assessments, lack of resources and materials, and budgetary restrictions for appropriate supplies and materials. This can put pressure on teachers to use direct, teacher-centered instruction, and rather, address subject areas in isolation [26]. Furthermore, teachers and tutors might be unable (or unwilling) to engage in alternative approaches to their discipline. Often "teachers teach the way they were taught" [27]. This could be attributed to a lack of experience in using active methods. The use of AR in classrooms can be expected to continue to face the same constraints that apply to any active learning pedagogy, when introduced in schools. Institutional constraints imposed by realizing the curriculum within a given time frame may cause difficulties in implementation [19]. Moreover, using AR comes with additional challenges like attention tunneling, when students experience high load on their working memory because of the AR application; usability difficulties, where AR systems fail to deliver a positive experience compared to physical or desktop-based alternatives; ineffective classroom integration, if AR can negatively impact on orchestration and organization of the classroom; and learner differences, where AR apps fail to adapt an effective teaching strategy for high- as well as low-achievers [21]. Learners might have difficulties maintaining superimposed information (due to poor tracking), or pay too much attention to virtual information [22]. This can even lead to AR being perceived an "intrusive technology" [22].

In our view, however, the biggest impediment to using AR technology as a tool in the classroom is certainly the lack of study materials, apps, and lesson scenarios available for STEAM teachers, 
contributing to many of the-in our view-secondary effects listed above. We suggest that many of the barriers summarized above can be overcome by training teachers how to use the new technology for Active Learning

\subsection{Learning by Doing}

The pedagogical approach taken in this study is Active Learning. It is a student-centric approach that involves students in the learning process and motivates them to take ownership of their own learning experience. Active Learning happens when students awaken their curiosity, working on self-set challenges they meet, while solving problems working on a project [28]. It requires students to use active inquiry, critical thinking, and problem-solving skills. Active participation of a student is necessary for the learning process to happen. Pedagogical strategies encouraging students to become actively engaged in their own learning can produce levels of understanding, retention, and transfer of knowledge significantly greater than those resulting from traditional classes [29]. Active Learning provides an environment for students to be curious, change the pace of the lesson as they need, and creatively increase students' involvement, motivation, excitement, attention, perceived helpfulness, and applicability of the knowledge learned in class [30]. Students engage in higher-order thinking such as analysis, synthesis, and evaluation [31]. The teacher assumes the role of a facilitator and learning becomes an authentic, engaging, and meaningful process-'Active'.

The research objective of this work was to investigate the use of Augmented Reality in support of STEAM teaching. While studies of AR in education have been conducted to inform the design of individual instructional applications, few studies so far have focused on creating a pedagogical pattern and providing teachers with the needed resources to apply it. Subsequently, we further describe first our specific Active Learning workshop format to fill this gap. Then, we turn to our case study and report the experience of teaching Augmented Reality Active Learning to a group of students and teachers. The results of the workshop in terms of student impact and learning experiences are reported. Students' performance is assessed as well as how the learning process was perceived by students. Possible integration of the Active Learning AR in curriculum is investigated. We conclude the article with a summary and an outlook on future work.

\section{The Augmented Reality Active Learning Methodology}

As already indicated above, Active Learning favors direct involvement of students in the process of learning, involving formats such as 'flipped classroom', 'learning by teaching', or the maybe less contentious 'small group discussion'. The key to Active Learning is to engage students in problemsolving [28], exposing them to complex situations that require their collaborative engagement to resolve, which typically involve jointly reflecting on and negotiating about the strategy and intended outcomes among those involved.

In our context of deploying Active Learning to facilitate the development of STEAM skills, we propose to use the task of coding Augmented Reality games as the focus object of education. The goal of STEM education is to learn how to solve real-life problems. The methodology presented in this paper integrates teaching AR and STEAM skills.

The activity itself is structured into a theoretical and a practical part. The theoretical part encompasses an introduction to Children's Games. In the practical part, participants discover the main ideas behind coding and get a chance to put their hands on a project, developing it from the initial idea right through to a working prototype. Students work in small groups and have the freedom to choose any type of game.

Over the course of two days, students are first given an introduction to coding using a hands-on tutorial for Unity game development. The methodology used follows the metaphor of 4-bricks (variables, condition, loop and read/write) and pseudo-code [32]. This is complemented by specifics needed for developing particular hardware platforms such as Microsoft Hololens or HTC Vive. Afterwards, students start with writing up the game mechanics in pseudo-code, then code the games 
in C\#, to then create all game assets in Unity. Finally, they build and deploy apps, and demo and share them with all participants.

The workshop format is designed to achieve a number of student learning outcomes related to STEAM skills. These goals were elaborated using the Revised Bloom's Taxonomy [33]. This taxonomy describes the cognitive processes of learning that is happening at each stage of the workshop. The Active Learning Augmented Reality workshop methodology is depicted in Figure 1 below.

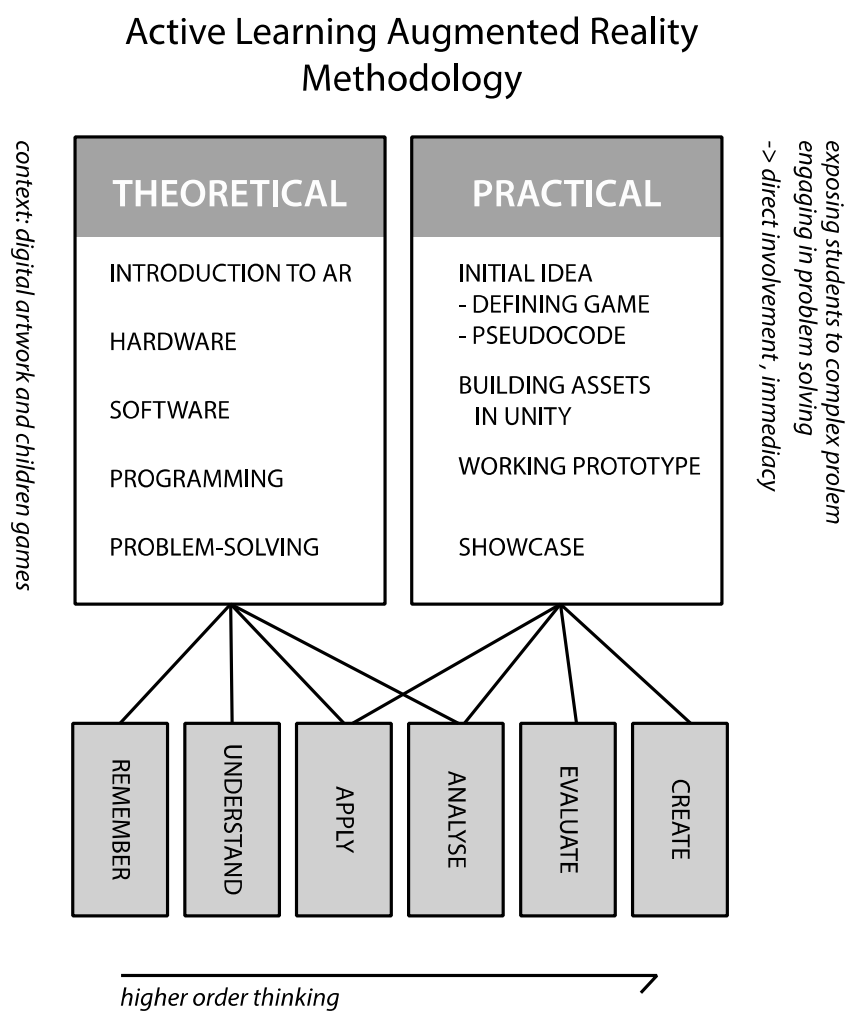

Figure 1. Active Learning Augmented Reality workshop methodology.

In the first part of the workshop, participants are introduced to the basic concepts of AR and programming. They gain knowledge about the topic (Bloom's 'remember') and understanding of the principles ('understand'). Further, they are tasked to do the exercises in Unity and Visual Studio which require analyzing ('analyze') and applying ('apply') the new knowledge to build a simple game. Finally, they are invited to build their own games ('create'). To do that, they need to apply ('apply') everything they have learned, evaluate their ideas in the AR context ('evaluate'), and create the game ('create'). Over the course of two days, they go through a full learning cycle to achieve the workshop's learning goals. The reader will find below the detailed description of the workshop methodology that was used to support learners in engaging with AR. We believe that it can serve as a useful resource for teachers.

1. Context: Presentation of the digital artwork, where the challenge is to convey the feelings and emotions using technology. Participants have a chance to experience immersive art.

2. Introduction to AR: Definitions, applications, examples.

3. Introduction to the hardware (Microsoft HoloLens): The facilitator explains how to use the device to one randomly chosen person, then participants instruct each other.

4. Introduction to the software: Unity (overview, short).

5. Introduction to Programming Basics: step-by-step tutorial in Unity: Create a game 'Roll a ball', a simple exercise, which allows participants to understand almost all Unity concepts: assets, how to import assets, how to modify assets, inspector, components, prefabs, transformations 
in 3D, rotations, scale, materials, texture, color, light, physics in Unity, rigid bodies, collisions, gravity, projectile). Building a working game in a short time (1-2 h) gives participants confidence that they can build a game.

6. Four-Bricks approach to programming: Idea that with only four concepts, it is possible to build an entire world (variables, read/write, tests and loops). Exercises in Visual Studio: participants need to understand the syntax, Visual Studio provides instant feedback. It is very intuitive. Additionally, participants work together, providing peer-to-peer support.

7. Introduction to Problem-Solving: Key concept for successful coding. Exercises and tips how to make efficient use of search engines and forums. Idea of collaborators and mentors.

8. Introduction to Children's Games: Artistic part of the workshop. Very simple games that do not require any special equipment (sticks, marbles, or friends). Discuss how such game can be translated into an Augmented Reality game. Creating groups and beginning to define logic behind the game, step-by-step; code on paper in 'pseudo code', using natural language.

9. Building of the games: Facilitator provides support, but does not give ready solutions, in order to keep participants interested and motivated.

10. Showcasing all games.

\section{Methodology}

The Active Learning AR format was originally conceived and iteratively refined from a series of five workshops delivered to different audiences (digital-art students in Mons, young professionals in different fields in Taiwan, teenagers in Brussels, teenagers in Oxford). Those workshops were organized in the scope of the ATLAS project and Augmented Reality for STEAM Education (STEAM-AR) project.

Yin [34] recommends resorting to case studies, when the form of the research question sets emphasis on 'how' and 'why', control of behavioral events is not given, and the focus is on contemporary events. The guiding research question for this work is "How and why does Active Learning with AR for STEAM education work?" In particular, we are interested in the impact of the intervention with regards to learning outcomes, satisfaction, and its overall feasibility. We chose a holistic, single-case design, focusing on one "critical case" [34] workshop of this series of five-critical as with regards to its role as an impact accelerator instrument, and as with regards to the workshop being off-site for the instructor, thereby taking the instructor out of their comfort zone.

By research design, we are able to secure "direct observation of the events being studied and interviews of the persons involved in the events" [34]. The interviews were conducted electronically, using open questions and written responses.

The research process can be outlined as depicted in Figure 2. First, we engaged in planning, and organizing the workshop. Then, regarding data collection, we collected all relevant documents (the original funding application for the impact accelerator account, the workshop rationale and program). We discussed what we observed at the workshop and arranged electronic interviews with open-ended questions. The method utilized at the workshop was an unstructured observation without predetermined variables or objectives. The researchers were simply immersed in the setting of the workshop.

In the data analysis phase, we investigated the documents, made and analyzed notes from memory, and conducted and inspected interviews. We examined the projects generated by students, similar to the approach chosen in [35]. This approach allowed us to assess students' problem-solving skills, focusing on outcomes of higher cognitive functions so important in teaching STEAM. Subsequently, this article was written up in order to present the findings. 


\begin{tabular}{l|l|l|l|l|l|}
\hline Planning & $\begin{array}{l}\text { Organisation of the } \\
\text { workshop and case study }\end{array}$ \\
\hline Data Collection & $\begin{array}{l}\text { Document gathering (funding } \\
\text { application, workshop rationale } \\
\text { and programme) } \\
\text { Observation }\end{array}$ \\
\hline Interviews \\
\hline Data Analysis & Document analysis \\
\hline Notes from memory \\
\hline Interview analysis \\
\hline Presentation & Results \\
\hline
\end{tabular}

Figure 2. The research process for the case study (own graphic).

\section{The Oxford Case Study}

The workshop investigated here took place at Oxford Brookes University over two days on 27-28 June 2019. The workshop was addressed to students of Year 10, 11, and 6th Form, with good ICT knowledge and interest in programming, as well as their ICT teachers and their teacher assistants. Participants were given the tools to create AR lesson content, which help trainers and teachers in creating their own AR learning experiences.

Nineteen participants took part in the workshop (4 teachers, 15 students). Participants were between 14 and 17 years old. Students formed groups of 2-3, working in small teams on their projects. Teachers were observing and supporting all groups with the technical challenges. Teachers were science teachers (computer science and math). Participants did not have any previous experience in AR but possessed basic coding skills. They all had a basic knowledge of programming (they knew one language, but it was not $\mathrm{C \# )}$.

We used the Microsoft HoloLens as AR delivery system hardware.

All the groups managed to create working prototypes, which were presented at the end of the workshop to all the participants. After the workshop, all the participants were asked to fill in a short anonymous questionnaire. The questionnaire asked for the main reasons and motivations to join the workshop, as well as benefits and challenges connected with the workshop. Additionally, the usefulness of the new knowledge and skills in learning STEAM subjects were queried. Eight $(42 \%$ of participants) questionnaires were returned, completed in full. Furthermore, interviews with teachers ( 2 out of 4 teachers) were conducted to investigate their view on possible integration of Active Learning AR into their teaching, and its place in the curriculum.

\section{Findings}

The workshop's outcomes assessment shows that all the groups demonstrated required skills to develop a basic Augmented Reality application. There were six teams, each team developed first a concept, reflected this in pseudo-code for their intended application (computational thinking), and then set out to create a working application prototype, providing evidence that they mastered the required level of coding (C\#, Unity) and computational thinking (4-Bricks). All teams succeeded. Mixed Reality captures of the developed applications in action are depicted in Figure 3 below. 
Catch the Cube

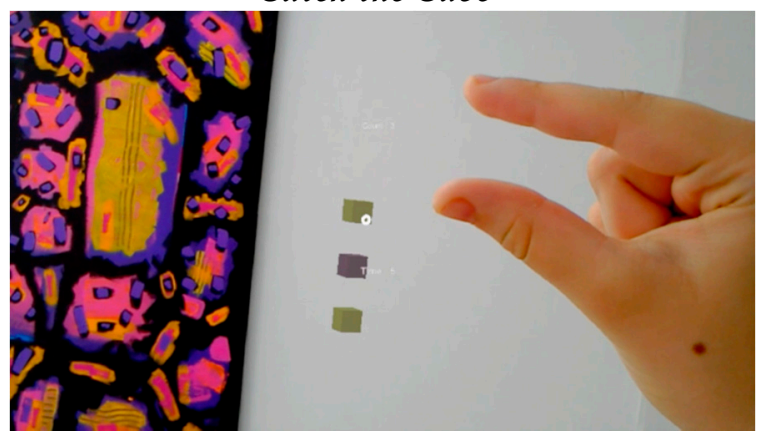

Bowling Chess

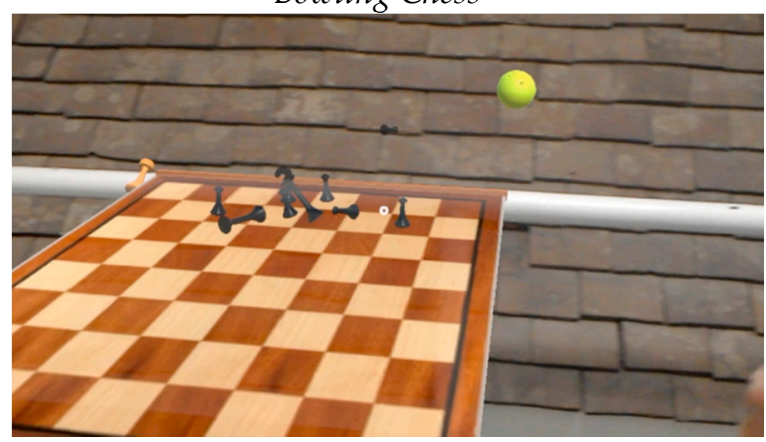

Raj Pac Man

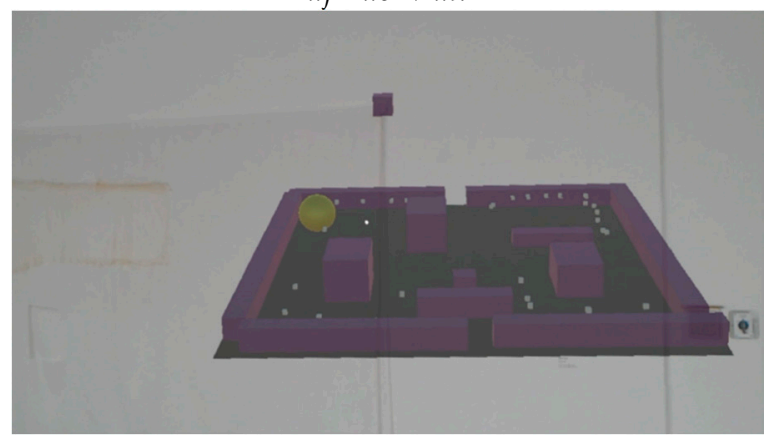

Pucket

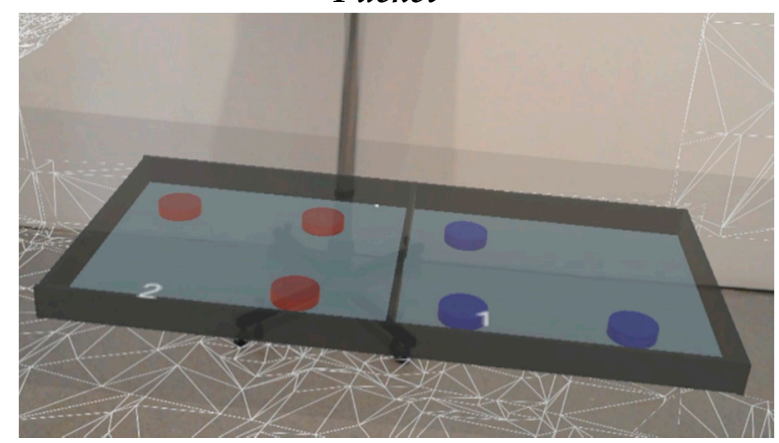

Kill that Pill

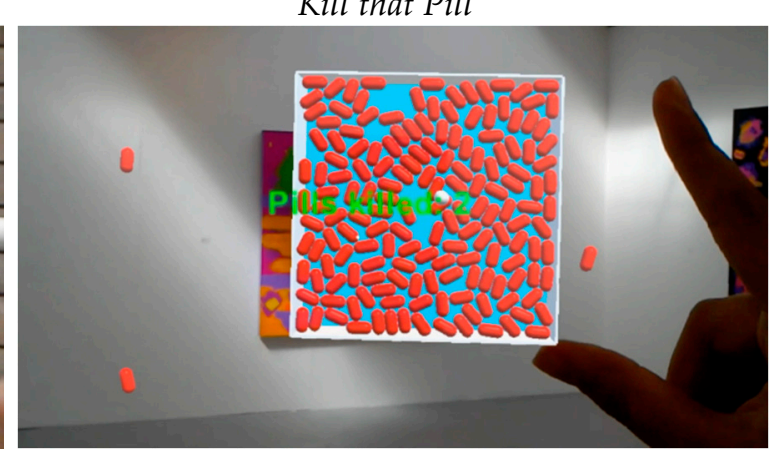

Bagatelle AR

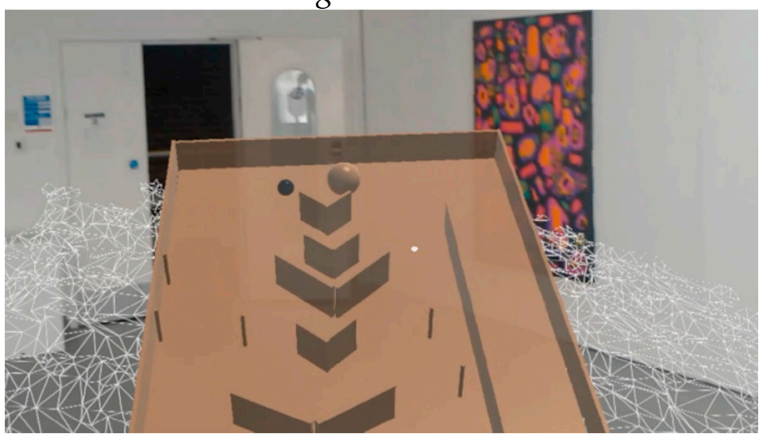

Figure 3. Mixed Reality captures of the games developed during the workshop.

Catch the Cube disperses cubes in the room using the spatial mapping. The user has to air-tap the cubes, trying to catch as many as possible in a given amount of time. Pucket challenges the user to swap sides of the game tiles by shooting them with air-tap through a little keyhole in the field-separating barrier. Bowling Chess uses chess pieces as bowling pins. Kill that Pill allows the user to hit pills out of their cage by shooting balls. Raj Pac Man lets the user collect dots using a Pac Man. In Bagatelle AR, the user catapults the ball up a ramp, with different points for landing in different bowls.

The workshop's level of difficulty was evaluated as straightforward (1/8), neutral (4/8), and difficult (challenging: 2/8; very challenging: 1/8). Most respondents, however, judged it as neutrally difficult.

As with regards to the knowledge and skills deployed in each of these projects, the following can be summarized. Kill that Pill, Bagatelle AR, Bowling Chess, and Pucket all involve working with the game mechanics engine, using rigid bodies, forces, and gravity to work out enjoyable game mechanics. All projects deploy computational geometry (ray-casting, geometry calculations to identify air-tap positions or affected game objects, deploying the Hololens Spatial Mapping). Moreover, they all required practicing basic computer-aided design skills, put into action when designing the visual assets. Each application has a unique look and feel, providing evidence of their artistic concept skill. Catch the Cube, Kill that Pill, and Pucket additionally involve timers or counters. 
We observed that participants engaged in teamwork, negotiating amongst themselves and with the present teachers and instructor what they should develop. Regarding project management, we observed that over the two days, participants became more proficient with regards to how to go about the development project, increasingly self-organizing testing and sharing of devices between the groups, prioritizing jobs, and sharing tasks and workload between members of the group, collaborating more and more as a team. Reducing the tutorial support pushed participants towards solving problems on their own. Pointing teams to solutions of other teams, and asking them to inquire how they solved a particular shared problem helped give the teams a sense of achievement and respect within their peer group.

To summarize, in our case, the skills identified include professional skills in software engineering, including coding skills, computational thinking, but also game mechanics (physics, forces, gravity), computational geometry, and computer-aided design. Additionally, we found evidence that the workshop motivates social and communication skills, project management, and problem-solving skills amongst the group of 21st-century skills [36], when conducted with such success in such collaborative setting. For an overview and the description of all skills motivated, see Table 1.

Table 1. Skills motivated by Active Learning AR.

\begin{tabular}{ccc}
\hline Group & Skill & Description \\
\hline \multirow{3}{*}{ Technical skills } & Coding & C\# development in Unity \\
& Computational Thinking & 4-Bricks, Pseudo-Code \\
& Computational Geometry & Physics, Forces, Gravity \\
& Lighting, Ray-Casting, Spatial Mapping \\
\hline \multirow{2}{*}{ Artistic skills } & Computer-Aided Design & Design of game assets \\
& Concept skills & Development of style and look \\
\hline \multirow{2}{*}{ 21st-century skills } & Social and Communication & Teamwork, negotiation skills \\
& Project Management & Leadership, resource management, \\
& Problem Solving & Pritizing, organization \\
& & Analytical skills \\
\hline
\end{tabular}

The qualitative feedback gathered shows the following picture. The Active Learning AR workshop generates positive students' feedback ("I really enjoyed the two days and hope that it will continue for all the other people who will get to experience it", "I liked it and found it beneficial").

In the questionnaire sent to all the participants, we also asked for their motivation to participate in the workshop. Only one person said that she/he knew AR already; most respondents (7/8) never used it before and were interested to find out more about AR ("Because I'd never used Augmented Reality before and it sounded fun", "Because I found the idea very interesting"). Two responses were indicating interest in pursuing education in Computer Science ("I like AR and I might want to do it as a job"). One person emphasized the uniqueness of the learning experience ("It seemed like an opportunity that I wouldn't get again").

Most of the participants (7/8) stated that they enjoyed the fact that in two days of the workshop, they were able to learn how to develop and play their own game ("Coding my own game and watching it progress in two days", "Being able to make the game actually work then playing it", "Programming it and testing it", "I liked playing the games (and making them)", "I liked the amazing sight of Augmented Reality that I had made, it was something I had only seen in films").

Many (5/8) participants appreciated new knowledge and coding skills ("It has helped me to use different coding languages and shown a new potential interest", "I can use basic skills in a new coding language", "I enjoyed using C sharp because it was a language I've never used. I also liked using Unity, I think it will come in handy in the future"). 
Students felt empowered by their new skills ("I feel more confident that I could write a computer game if I wanted to", "I can use my knowledge how to fix issues using more creative methods in everyday life").

All the participants agreed that AR technology could be used in schools to help learning; they gave many examples ("I think it could be used in schools", "I think it could be used to help with certain subjects that students could use to interact with the topics. Like in math with shapes and angles, kids can interact to understand the different concepts", "It could be used to show biology diagrams in 3D", " ... more interactive work, especially to help explain things or do science practicals in AR", " ... using things like virtual flashcards to learn", "It would be more appealing to children as it's something they've never seen").

The most often used descriptors have been "interesting", "useful", and "fun". One person particularly appreciated the open format of the activity ("I liked having freedom to make whatever game we wanted").

Participants shared their opinions about the challenges of using AR in educational settings. Most students (5/8) suggested that there is a need for assistance with writing a code ("More help with the coding"). An issue is the hardware, as students had to share a few devices. They reported that this created a lot of waiting and wasting time (" ... waiting for the AR glasses is very boring and they seem to take a while to set up"). Students were limited to the duration of the workshop to explore and experiment with their applications ("I can't use my new AR knowledge because I don't have the equipment to test it out"). They also requested more theoretical background to give them better understanding ("A longer time and more introduction to give the foundations").

We observed, however, further challenges the participants were facing. With the lack of Wi-Fi in the workshop room (all computers are cable connected), it was not possible to simultaneously use the Internet and the so-called 'holographic remoting' of the Microsoft Hololens. Holographic remoting allows directly executing the work in progress on the device using the Unity Editor, thus avoiding lengthy build times between tests. Participants therefore needed to build their app to test, which takes 5 to $10 \mathrm{~min}$ on the computers available in the pool. It is tricky to quickly and directly see the effect of the code, which is particularly important for beginners. Even though rental models exist that bring the price down, the purchase price for the Microsoft Hololens 2 is still high and may therefore prevent schools as well as students from buying, resulting in reducing the likelihood to continue development outside of the workshop. A lower cost alternative could be using AR on mobile phones, which are currently more prevalent in education [17]. There are several STEAM-focused AR studies that back up this type of use [19,37]. The technical capabilities, however, are not comparable, and even on latest generation smart phones compatible with ARKit and ARCore, the experience is diminished (e.g., lesser display quality, missing hologram effect, no hands-free scenarios possible, no spatial sound, reduced projection stability). We therefore decided, in particular for motivating reasons, to use Microsoft Hololens in the workshop.

\section{Discussion}

Ibanez and Delgado-Kloos [37] suggest that AR is becoming a popular technology in education, as it has potential for pedagogical applications supporting learning and teaching. They claim that the main advantages of AR are its potential learning gain, increased motivation, responsive interaction, and the potential for collaboration. When applied right, they say, AR can be helpful in increasing students' motivation, fostering collaboration among students, developing spatial abilities, and improving performance in physical tasks.

Our case study supports this: We found that the Active Learning AR methodology can be an effective tool in teaching students STEAM's technical as well as artistic skills, plus, additionally, a range of complementary 21st-century skills. The findings demonstrate the ability of the students to learn the basics of $\mathrm{AR}$ and develop working prototypes, developing and practicing complex skills such as working with physics simulations, computational geometry, and coding/computational thinking. 
Moreover, the workshop stimulates the artistic soul, and offers students a chance to develop and practice game concept skills and apply computer-aided design. Finally, among the 21st-century skills, the format requires mastering social and communication skills, project management, and critical thinking.

We collected additional feedback in a follow-up to this case study from the participants of the other four workshops, and found the following regarding the questions we asked about why they participated, what they particularly enjoyed, what they would change, how they could use the new knowledge and skills, and whether they think the technology can be used in schools to help learning. The motivation to participate in the workshop was mainly the wish to learn, explore AR, and interest in the topic (" ... the immersive experience fascinating"). Participants enjoyed practical, hands-on activities and the process of creation ("Building a world in AR is amazing", " ... the freedom to create", "... building my own creation"). They also appreciated the part when they could deploy and try games (" .. play together our games", " .. playing the game designed by the others and having fun"). Additionally, they were fond of getting to know each other, as well as enjoying conversations and emotions that occurred in the process. They are pleased that they get the new knowledge and skills and they can use it ("Now I understand how it works, how games are made", "I can make my own AR experience"). For many participants, the workshop was challenging, and they would like to have more time to work on their projects.

Furthermore, we asked how AR could be used at the educational settings. Participants shared their opinions that AR could be implemented to teach and learn as it relates to math. Moreover, learning more about the work behind games has a potential to help kids to increase learning motivation on coding or visual design, game design, story writing, etc. Another example listed distant lessons, usefulness for disabled/less-able students and art schools. However, a limitation is seen in the access to the AR equipment and need for basic coding knowledge.

The positive student feedback and the neutral level of difficulty suggest that the methodology can be adopted in the classroom successfully to create an engaging environment for learning, triggering students' curiosity. The process and its outcomes are enjoyable for students. This illustrates the capability of the format to create new learning experiences for students in STEAM and beyond. Once engaged in Active Learning, students start to notice the usefulness of the concept, problem, or challenge they are working on. The methodology of the workshop is built in a way that it allows sustaining its learning outcomes. All the elements of the games that were created can be accessed on the PC and the holographic applications can be tested using an emulator. Students can keep working on their applications. This study did not, however, follow up with the participants to find out whether they engaged in sustaining the results.

Following the workshop, we invited two mathematics teachers to discuss what their opinion is about the Active Learning AR method and what their view is regarding possible integration of this innovative approach to the curriculum. Teachers shared that coding is encouraged, though not required in the curriculum for math. Similarly, problem-solving and project learning is already embedded in the curriculum, employed to engage students in mathematical thinking, especially in further mathematics. If A-levels further math is chosen, then coding (in Phyton) can be used to do calculations in number theory. Teachers are already using software like GeoGebra to visualize geometry, algebra, statistics, and calculus. There are already several examples of using GeoGebra Augmented Reality to create dynamic, student-centered, exploratory learning environments. One of the examples is depicted below in Figure 4. 


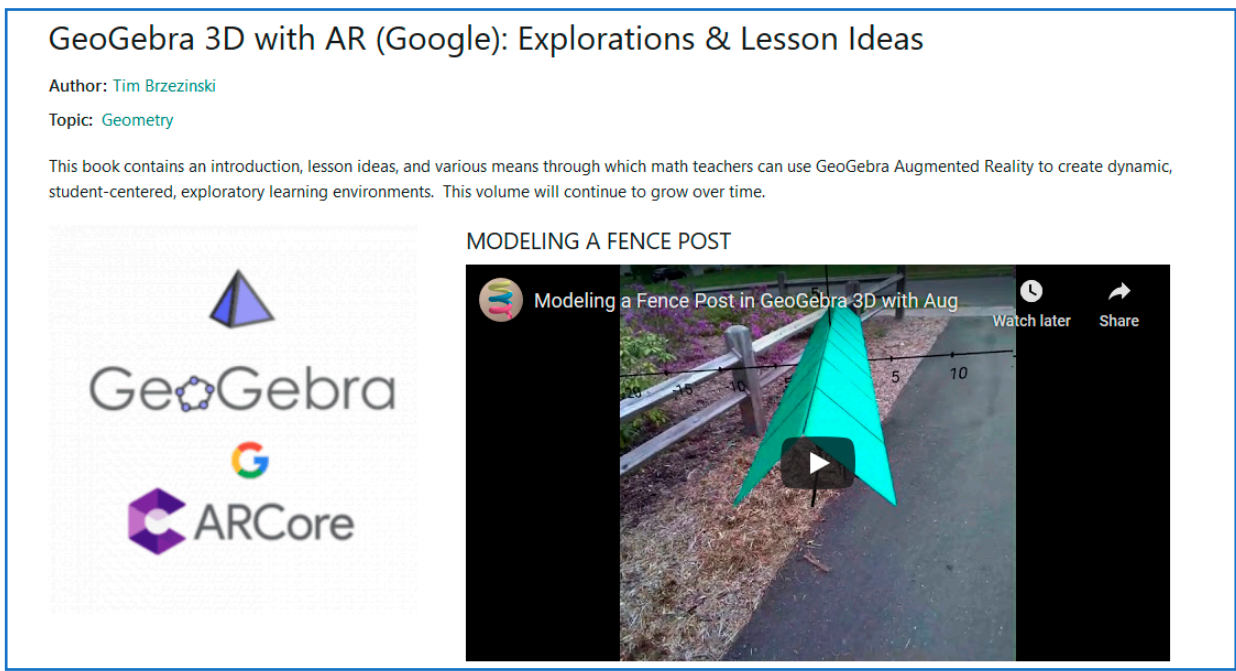

Figure 4. Example of AR used for math teaching [38].

$\mathrm{AR}$, according to the teachers, could be especially useful to visualize vectors, geometry, and trigonometry. When it comes to its place in the curriculum, teachers suggest that it could be integrated into the Extended Essay and Extended Project Qualification (EPQ). The Extended Essay is part of the core of the International Baccalaureate (IB) system that is compulsory for all students taking the Diploma course (years 12 and 13 in the UK). EPQ is associated with the A-level program and is an 'add-on' that students can take. Some students may choose a math-related topic, within which AR could fit nicely.

The most prevalent limitation can certainly be identified in the hardware and its availability. On the one side, the classroom network setup prevented the use of holographic remoting, slowing participants down in testing and deploying by the click of a button, the smart glasses devices. On the other side, hardware like the Microsoft Hololens is still in a premium price segment, preventing many schools to buy these for the classroom, and many more students to buy them for home. Solutions to the holographic remoting problem are to either fit the computers with portable USB Wi-Fi adapters, or to switch the platform to another; also more affordable hardware (analogical to the VR Oculus Quest). This would also allow them to purchase a device for home use, so they can work on their projects afterwards. Such devices could bring a real change in teaching AR. Alternatively, plan-based and rental models are now available for Hololens II, keeping monthly or event-based costs for devices to a minimum.

\section{Conclusions and Outlook}

The academic community is continuously researching pedagogical approaches for teaching STEAM subjects that are prone to have better potential professional learning outcomes, while having a positive impact on the development of students' 21st-century skills. With this contribution, we make a proposal for Active Learning AR as a methodology to motivate the development of both. This paper suggests a shift from lecture-based teaching to active learning. We prototype the Active Learning AR format to be embedded into curricula in the future. Using this methodology can be especially useful for the students in years 12 and 13 preparing their university application (Extended Essay and Extended Project Qualification). Students could develop a final project and gain a qualification as skills evidence for the university application process. This approach has a chance to change learning of STEAM subjects from mere remembering to facilitating analyzing and understanding of studied concepts.

In line with other studies, our case study results agree that using AR technology increases the motivation of workshop participants to learn and how they perceive STEAM subjects. We observed that it is happening, particularly, when and because students' curiosity is triggered and they are challenged to create their own project, adding to their enjoyment. 
Beyond this contribution, we believe that professional development programs could help further improve educators' confidence levels and proficiency in using AR, helping them move beyond their restricted views regarding the role of technology in teaching and learning [39], and implementing AR in STEAM at scale. Teachers who are interested in this AR Active Learning approach need support in creating teaching materials and lesson scenarios. They should be given opportunities to learn and develop their skills.

The limitations of our study were as follows. The workshop organized in the scope of the research was a pilot with a limited number of participants. We therefore would like to stress our findings presented in this paper are built on a single case, with a small number of students interviewed. It was also a self-selecting sample, which is not a representative sample of all populations of students. Moreover, it relied on learners' self-reports of usability, preference, and efficiency to evaluate the learning effects. There is evidence to suggest that some types of STEAM- focused activities are provided to selected or self-selecting groups of pupils [6]. The data collected to evaluate the workshop comes from subjective indicators. Furthermore, as the researchers were immersed in the setting to get a direct access to the researched case, there is a risk that such methodology comes with high levels of observer bias, and it can influence participants' behavior.

Another limitation of the study is an assumption that AR is a suitable technology for all types of learners. There are limited studies investigating exploiting AR in education for children belonging to disadvantaged or risk groups, like children with special educational needs or children from families with low socioeconomic status, e.g., [40]. There is a need to include these groups to future studies. Future studies may want to assess quantitatively the outcomes of learning and study less represented communities. Many research questions, however, remain unanswered. For example, in agreement with Lasica et al. [41], we suggest that more research is needed to help with practical considerations such as regarding the associated cost structure, technical requirements for equipment, or best practices of how to embed innovative technology as a standard element in the syllabus [41]. More guidance is needed to facilitate the incorporation of creative and innovative projects into teaching practice. More research is also needed regarding employability aspects, investigating whether future employers would be keen to hire students who conducted part of their studies using AR [41].

The presented study is limited to a single case. To gather more evidence on the educational value of AR, controlled and comprehensive evaluation studies that include a large sample are needed. We aim to engage in future studies to further reveal the educational value of Active Learning Augmented Reality. This could involve embedding the presented format into specific curriculum practices at a larger scale, thus investigating its implementation into regulated teaching.

We conclude that the approach presented in this paper shows that it is achievable to promote the development of STEAM skills with Active Learning, triggering curiosity of students, and giving them control of their own learning experience. Introducing AR technology to the classroom shows high potential for academic gains for students, in particular regarding their technical, artistic, and 21st-century skills development.

Author Contributions: Conceptualization, J.J.; Funding acquisition, F.W.; Investigation, Y.D.; Methodology, Y.D.; Project administration, F.W.; Resources, Y.D.; Writing, J.J.; Writing, F.W. All authors have read and agreed to the published version of the manuscript.

Funding: This research was financially supported by Oxford Brookes University as part of the Impact Acceleration Account (IAA) project 'STEAM Education with Augmented Reality' (STEAM-AR). Analysis and write up were further supported by the European Union under the Horizon 2020 Programme, as part of the ARETE project (grant agreement No. 856533).

Acknowledgments: The authors gratefully acknowledge all the students and teachers who participated in the workshops and teachers who provided additional information and feedback: James Watt from Oxford High School GDST, Richard Pugsley from OIC Oxford and Grahame Hale from EF Academy in Oxford.

Conflicts of Interest: The authors declare no conflict of interest. 


\section{References}

1. Cornelius, D. The Education and Skills Gap: A Global Crisis. Tech. Connect. Educ. Careers 2011, 86, 50-55.

2. Leahy, S.M.; Holland, C.; Ward, F. The digital frontier: Envisioning future technologies impact on the classroom. Futures 2019, 113, 102422. [CrossRef]

3. Industrial Strategy: Building a Britain Fit for the Future. 2017. Available online: https://www.gov.uk/ government/publications/industrial-strategy-building-a-britain-fit-for-the-future (accessed on 31 July 2020).

4. Ravagnoloa, L.; Helinb, K.; Mussoc, I.; Sapone, R.; Vizzi, C.; Wild, F.; Vovk, A.; Limbu, B.; Ransley, M.; Smith, C.; et al. Enhancing Crew Training for Exploration Missions: The WEKIT experience. In Proceedings of the 70th International Astronautical Congress (IAC), Washington, DC, USA, 21-25 October 2019.

5. McNulty, S. Skills Crisis: Managing the Digital Diversity; EGov Innovation: Sierre, Switzerland, 2019.

6. The UK STEM Education Landscape-Royal Academy of Engineering. 2016. Available online: https://www. raeng.org.uk/publications/reports/uk-stem-education-landscape (accessed on 31 July 2020).

7. Success Through STEM: STEM Strategy: In Response to the 'Report of the STEM Review': Helping to Empower Future Generations Through Science, Technology, Engineering and Mathematics to Grow a Dynamic, Innovative Economy. 2011. Available online: https://dera.ioe.ac.uk/10407 (accessed on 31 July 2020).

8. GOV.UK. Statutory Guidance National Curriculum in England: Science Programmes of Study. 2015. Available online: https://www.gov.uk/government/publications/national-curriculum-in-england-science-programmesof-study/national-curriculum-in-england-science-programmes-of-study (accessed on 31 July 2020).

9. Connor, A.; Karmokar, S.; Whittington, C. From STEM to STEAM: Strategies for enhancing engineering \& technology education. Int. J. Eng. Pedagog. 2015, 5, 37-47.

10. Watson, A.; Watson, G. Transitioning STEM to STEAM: Reformation of Engineering Education. J. Qual. Particip. 2013, 36, 1-5.

11. Connelly, G. Art puts the STEAM in STEM. Principal 2012, 92, 48.

12. Schmalstieg, D.; Höllerer, T. Augmented Reality-Principles and Practice; Addison-Wesley Professional: Boston, MA, USA, 2016.

13. Azuma, R.T. A Survey of Augmented Reality. Presence Teleoperators Virtual Environ. 1997, 6, 355-385. [CrossRef]

14. Lee, K. Augmented reality in education and training. TechTrends 2012, 56, 13-21. [CrossRef]

15. Azuma, R.; Billinghurst, M.; Klinker, G. Special Section on Mobile Augmented Reality. Comput. Graph. 2011, 35, 7-8. [CrossRef]

16. Maas, M.J.; Hughes, J. Virtual, augmented and mixed reality in K-12 education: A review of the literature. Technol. Pedagog. Educ. 2020, 29, 231-249. [CrossRef]

17. Akçayır, M.; Akçayır, G. Advantages and challenges associated with augmented reality for education: A systematic review of the literature. Educ. Res. Rev. 2017, 20,1-11. [CrossRef]

18. Sirakaya, M.; Sirakaya, D.A. Augmented reality in STEM education: A systematic review. Interact. Learn. Environ. 2020, 142, 1-14. [CrossRef]

19. Wu, H.-K.; Lee, S.W.-Y.; Chang, H.-Y.; Liang, J.-C. Current status, opportunities and challenges of augmented reality in education. Comput. Educ. 2013, 62, 41-49. [CrossRef]

20. Chen, P.; Liu, X.; Cheng, W.H.; Huang, R. A Review of Using Augmented Reality in Education from 2011 to 2016; Springer: New York, NY, USA, 2017.

21. Radu, I. Why should my students use AR? A comparative review of the educational impacts of augmented-Reality. In Proceedings of the 2012 IEEE International Symposium on Mixed and Augmented Reality (ISMAR), Atlanta, GA, USA, 5-8 November 2012.

22. Bacca, J.; Baldiris, S.; Fabregat, R.; Graf, S.; Kinshuk. Augmented reality trends in education: A systematic reviewof research and applications. J. Educ. Technol. Soc. 2014, 17, 133-149.

23. Fidan, M.; Tuncel, M.; Mustafa, F. Integrating augmented reality into problem based learning: The effects on learning achievement and attitude in physics education. Comput. Educ. 2019, 142, 103635. [CrossRef]

24. Chiu, J.L.; Dejaegher, C.J.; Chao, J. The effects of augmented virtual science laboratories on middle school students' understanding of gas properties. Comput. Educ. 2015, 85, 59-73. [CrossRef]

25. Shekhar, P.; Borrego, M. 'Not hard to sway': A case study of student engagement in two large engineering classes. Eur. J. Eng. Educ. 2016, 43, 585-596. [CrossRef] 
26. Harper, C. The steam-powered classroom. Educ. Leadersh. 2017, 75, 70-74.

27. Lunenberg, M.; Korthagen, F.; Swennen, A. The teacher educator as a role model. Teach. Teach. Educ. 2007, 23, 586-601. [CrossRef]

28. Christie, M.; De Graaff, E. The philosophical and pedagogical underpinnings of Active Learning in Engineering Education. Eur. J. Eng. Educ. 2016, 42, 5-16. [CrossRef]

29. DeHaan, R.L. The Impending Revolution in Undergraduate Science Education. J. Sci. Educ. Technol. 2005, 14, 253-269. [CrossRef]

30. Koch, F.D.; Dirsch-Weigand, A.; Awolin, M.; Pinkelman, R.J.; Hampe, M.J. Motivating first-year university students by interdisciplinary study projects. Eur. J. Eng. Educ. 2017, 42, 1-15. [CrossRef]

31. Dharshini, P.; Sundaram, B.V. Evaluation of higher-order thinking skills using learning style in an undergraduate engineering in flipped classroom. Comput. Appl. Eng. Educ. 2018, 26, 2237-2254.

32. Darmangeat, C. Algorithmique et Programmation Pour Non-Matheux, Lecture Notes, Paris 7 University. 2013. Available online: http://pise.info/algo/introduction.htm (accessed on 31 July 2020).

33. Anderson, W.L.; Krathwohl, R.D.; Airasian, W.P.; Cruikshank, A.K.; Mayer, E.R.; Pintrich, R.; Raths, J.; Wittrock, M.C. A Taxonomy for Learning, Teaching, and Assessing: A Revision of Bloom's Taxonomy of Educational Objectives; Addison Wesley Longman: Boston, MA, USA, 2001.

34. Yin, R.K. Case Study Research: Design and Methods, 3rd ed.; Applied Social Research Methods Series V. Sage Publications: Thousand Oaks, CA, USA, 2003.

35. Suarez, A.; Specht, M.; Prinsen, F.; Kalz, M.; Ternier, S. A review of the types of mobile activities in mobile inquiry-based learning. Comput. Educ. 2018, 118, 38-55. [CrossRef]

36. UNESCO International Bureau of Education. IBE Glossary of Curriculum Terminology. 2013. Available online: http://www.ibe.unesco.org/ (accessed on 29 February 2020).

37. Ibanez, M.B.; Kloos, C.D. Augmented reality for STEM learning: A systematic review. Comput. Educ. 2018, 123, 109-123. [CrossRef]

38. Brzezinski, T. GeoGebra 3D with AR (Google): Exploration \& Lesson Ideas. Available online: https: //www.geogebra.org/m/qbxbcmqw (accessed on 31 July 2020).

39. Meletiou-Mavrotheris, M.; Charalambous, C.; Mavrou, K. Augmented Reading Through Emerging Technologies: The Living Book Approach to Teachers' Professional Development. In Emerging Technologies and Pedagogies in the Curriculum. Bridging Human and Machine: Future Education with Intelligence; Yu, S., Ally, M., Tsinakos, A., Eds.; Springer: Singapore, 2020.

40. Turcanu, D.C.; Prodea, B.M.; Constantin, C. The Opportunity of Using Augmented Reality in Educating Disadvantaged Children, Bulletin of the Transilvania University of Brasov. Series V. Econ. Sci. 2018, 11, 71-78.

41. Lasica, I.; Katzis, K.; Meletiou-Mavrotheris, M.; Dimopoulos, C. Augmented reality in laboratory-based education: Could it change the way students decide about their future studies? In Proceedings of the 2017 IEEE Global Engineering Education Conference (EDUCON), Athens, Greece, 26-28 April 2017; pp. 1473-1476. 